\title{
Identification of Mercury Levels on the Operator's FaceMask During the Removal Of Dental Amalgamas: Pilot Study
}

\author{
Silverio Jafet Vázquez Alcaraz*, Eduardo Sandoval Sandoval, Richard Chung, Michelle Patricia García Patiño \\ and Javier Alejandro Cornejo Vázquez
}

Faculty of Dentistry, University Autonomous of Guadalajara, México

Submission: December 22, 2016; Published: January 09, 2017

*Corresponding author: Silverio Jafet Vázquez Alcaraz, Coordinator of the occupational Health program in Stomatology, Faculty of Dentistry, University Autonomous of Guadalajara, Dental Clinic: Escorza 515, Americana, 44190 Guadalajara, Sebastián Bach 4754, Prados de Guadalupe, Zapopan, Jalisco, México, Tel: +55 (33) 3336-292077; Email: silerio.vazquez@mail.uag.mx

\section{Abstract}

Several cases of mercury poisoning and embryotoxicity among dental personnel have been documented. The exposure level of mercury vapor upon removal of an amalgam restoration, without water irrigation and without ventilation is $0.19 \mathrm{mg} / \mathrm{m} 3$. Dentists exposed to $16.7 \mu \mathrm{g} /$ $\mathrm{m} 3$ of mercury in the air showed deficiencies in logic and vision. Facemasks have been used to reduce workers' exposure to infectious and toxic aerosol material.

Objective: Identify the levels of mercury in the dental operator's face mask after the removal of dental amalgams by detection in atomic absorption spectrophotometry.

Methods and Materials: Eight patients who required dental amalgam removal treatment in Operatory Dental Clinic at the Universidad Autónoma de Guadajarawere considered in this pilot study. The facemasks were used as specimens. An atomic absorption spectrophotometer was used to identify the amount of mercury ions in the facemasks used. The data was analyzed in central tendency parameters.

Results: Specimens A, F and G showed the highest levels of mercury found in the face masks (30.8ppb, 17.0ppb, 16.7 ppb respectively). Specimens B, D, E and H have baseline mercury levels of $250 \mathrm{ng} /$ facemask.

Conclusion: Significant levels of mercury are discovered on the outer surface of the facemasks of the personal protective facemask used during the removal of dental amalgams, which are around $4.91 \mathrm{ppb}$ and $291.25 \mathrm{ng} /$ facemask.

Keywords: Mercury; Amalgam; Removal; Dentistry; Face masks; Occupational health

Abbreviations: UAG: University Autonomous of Guadalajara; FO: Faculty of Dentistry; CLIO: Dental Clinic Odontology; CIDI: Research Center for Industrial Development

\section{Introduction}

Currently, there is a worldwide trend to rule out the use of mercury from human activities. In dentistry, there is a great controversy about the safety of the use of dental amalgam in patients and there have been attempts to demonstrate the occupational risk to which dentists are exposed by developing dentistry techniques that do not use mercury [1].

The fact that an amalgam contains mercury has raised some health and safety concerns. In assessing the occupational risk to which dental personnel are exposed to mercury, it has been observed that this depends on techniques used during the preparation of the amalgam and it has been determined that these risks can be minimized by performing modern practices complying with standards for Handling of hazardous substances [2].

Several cases of mercury poisoning and embryotoxicity among dental personnel have recently been documented [3]. In fact, exposure to inorganic mercury has been found to increase levels of this metal in blood plasma and urine [4]. In a dental practice, dentists and their dental assistants are at risk because of the use of mercury in the preparation of amalgam as they are chronically exposed to the vapor [5]. In Singapore, 96 dentists examined, exposed to $16.7 \mu \mathrm{g} / \mathrm{m}^{3}$ of mercury $(\mathrm{Hg})$ in the air, were deficient in both memory and vision [6]. Dental workers, who 
work with amalgams, have a reduced fertility rate, low conception possibilities, and their children have a lower IQ compared to the general population [7]. A dental amalgam is an alloy of mercury, silver, copper, and tin and may also contain palladium, zinc, and other elements to improve handling characteristics and clinical performance. Amalgams have been used by dentists for over 100 years because it is very durable and more accessible than other dental restorative materials [2].

In a study by Svare et al. [8] there was an increase in mercury levels in air exhaled by people with dental amalgams with a registry of $0.01374 \mathrm{mg} / \mathrm{m}^{3}$ after chewing. That is, people with dental amalgams are potentially exposed to mercury with an average of about $13.74 \mu \mathrm{g} / \mathrm{m}^{3}$ every day [9]. At the dental clinic, concerns about toxicity problems include: inhalation of mercury vapor and amalgam powder; ingestion of amalgam; allergy to mercury; and environmental considerations. Inhalation and ingestion of mercury from dental amalgams may occur during placement, polishing, or removal of the restoration, or during mastication [10].

According to OSHA (Occupational Safety and Health Administration), the permissible exposure limit is $0.1 \mathrm{mg} /$ $\mathrm{m}^{3}$ (vapor). NIOSH (The National Institute for Occupational Safety and Health) stated that the maximum exposure limit or immediate danger to life or health limit is $10 \mathrm{mg} / \mathrm{m}^{3}$ [8]. In the Rugg-Gunn study, the mercury vapor exposure level upon removal of an amalgam restoration without water irrigation and without ventilation was $0.19 \mathrm{mg} / \mathrm{m} 3$, which is above the OSHA Permissible Exposure Limit [11].

Although the ADA has reported that amalgam restorations used in dentistry do not necessarily pose a health risk, dentists and dental staff should decrease mercury exposure to dental amalgams [2].

The ADA also published an article on how to handle and dispose of amalgam waste [12]. These include (but are not limited to): The use of traps for residual mercury, install amalgam separators that comply with ISO 111432, use of a high suction aspirator for the removal of amalgams, inspection and cleaning of the vapor traps and collect and recycle the dental amalgam.

The masks have the function of protecting our nasal mucosa and the entire oral cavity, avoiding the contamination by aerosols originated by the rotary instruments of the dental office [13].

The facemasks, surgical mask, or hygiene mask are designed to avoid the spread of microorganisms that are lodged in the mouth, nose, and throat avoiding the contamination between the operator and the patient. They operate in dual forms, during the exhalation of the operator, the air of the nose and mouth exits at a certain speed and is directed frontally preventing its dissemination [14], and is capable of filtering particles suspended in the air prone to aspiration by the operator as part of the contamination of the work area during dental treatment [15].
Facemasks have been used to reduce workers' exposure to infectious and toxic aerosol material occurring through splashes and droplets, primarily. However, their filtration capacity is very limited because during the filtration tests they do not reach the minimum 95\% required to provide respiratory protection [16], even when using up to five masks at the same time [17].

The particles that should be able to filter the masks should be relatively thick, between 3 and 8 microns [14,15], and $0.1 \mu \mathrm{m}$ for laser use (thus protecting the person using them against smoke of the laser) [18].

The facemasks are made of synthetic material and some have a polypropylene cover. Some can be smooth / pleated (others have a rigid shape of the contour of the face) and are looped around the ears with elastic strings or with strips to better fit on the nose and over the mouth. They are not designed to provide a facial seal and thus allow filtration to enter through the edges of the mask when the user inhales [18]. The objective of this pilot study is to identify the mercury levels in a dental operator's facemask at the end of removal an amalgam filling by detection in an atomic absorption spectrophotometry at theOperatory section of CLIO UAG during the month of July - September 2016.

\section{Materials and Methods}

Eight patients who required dental amalgam removal treatment at the Operatory section of CLIO UAG were considered in this pilot study. All patients received and signed informed consent for the operative amalgam removal procedure. The operators were dental undergraduate students and postgraduate residents of FO UAG who had indication of amalgam removal as an operative treatment regardless of tooth. The personal protection equipment for dental procedures was designated by the CLIO UAG, where the facemask was used as a specimen. Patients were protected with the use of a surgical disposable scrub gowns to reduce aerosol exposure during the dental amalgam removal procedure.

Eight facemasks were obtained, made of polypropylene of double cloth weighing 35 grams, with intermediate filter, pleated, with nasal adjuster, and an elastic cord to the ears. The brand name of the facemask is GRUPREYSA, and this was the facemask used in the removal of dental amalgams. One new mask per patient was used as a control variable.

A rubber dam was used to isolate the tooth being treated to reduce the amount of amalgam aspiration by the patient orally and respiratory. We used a high speed dental hand piece with sterilized \# 4 carbide ball for the removal of the amalgam. Constant irrigation and a conventional ejector were used for the aspiration of water during the procedure, with an average time of 15 minutes per patient. The facemasks were removed according to the safety protocols of the CLIO UAG and immediately deposited in a self-sealed plastic bag to be taken for analysis.

An Atomic Absorption Spectrophotometer (EQQ 289) was used for the identification of mercury ions in the facemasks at 
the Research Center for Industrial Development (CIDI) at UAG. The masks were weighed on an analytical balance individually. Subsequently the facemasks were placed in individual flask and immersed in $50 \mathrm{ml}$ of $3 \%$ hydrochloric acid $(\mathrm{HCl})$ for 24 hours. Next the facemasks were moved and placed in to a $250 \mathrm{ml}$ volumetric matrix containing: $0.5069 \mathrm{~g}$ of sodium borohydride ( $\mathrm{NaBH} 4)$ and $2.5 \mathrm{ml}$ of dilute $5 \%$ sodium hydroxide $(\mathrm{NaOH})$ was added. The contents were to be measured and dissolved with $250 \mathrm{ml}$ distilled water to determine the levels of mercury through the spectrophotometry study of atomic absorption of the facemask used by the operators during the process of dental amalgam removal. The data were analyzed using an excel spreadsheet to obtain central trend parameters.

\section{Results}

Table 1: Results obtained by the atomic absorption spectrophotometer of the mercury identification levels preceding the removal of dental amalgams on the facemasks used by the operator.

\begin{tabular}{|c|c|c|c|}
\hline Specimens & Mercury Levels in ppb* & $\begin{array}{l}\text { Mercury levels in relation to } \mathrm{ppb} / \\
\text { facemask** }\end{array}$ & $\begin{array}{l}\text { Mercury levels in relation to } \\
\text { ng/facemask }\end{array}$ \\
\hline A & 30.8 & $\begin{array}{c}(50 \mathrm{~mL} / 25 \mathrm{~mL})(50 \mathrm{~mL} / 2.5073 \mathrm{~g})=1128.41 \\
\mathrm{ppb}\end{array}$ & 3080 \\
\hline B & 1.76 & $\begin{array}{c}\text { less than } 5 \mathrm{ppb} *(50 \mathrm{ml} / 2.4660 \mathrm{~g})=\text { less than } \\
101.38 \mathrm{ppb}\end{array}$ & 250 \\
\hline $\mathrm{C}$ & 6.65 & $6.65 \mathrm{ppb}(50 \mathrm{ml} / 2.5039 \mathrm{~g})=132.79 \mathrm{ppb}$ & 332.5 \\
\hline $\mathrm{D}$ & 2.36 & $\begin{array}{c}\text { less than } 5 \mathrm{ppb} *(50 \mathrm{~mL} / 2.5119 \mathrm{~g})=\text { less than } \\
99.53 \mathrm{ppb}\end{array}$ & 250 \\
\hline $\mathrm{E}$ & 1.83 & $\begin{array}{c}\text { less than } 5 \mathrm{ppb}^{*}(50 \mathrm{~mL} / 2.5776 \mathrm{~g})=\text { less than } \\
96.99 \mathrm{ppb}\end{array}$ & 250 \\
\hline $\mathrm{F}$ & 17.0 & $\begin{array}{c}17.0 \mathrm{ppb}(25 \mathrm{~mL} / 10 \mathrm{~mL})(50 \mathrm{~mL} / 2.5354 \mathrm{~g})= \\
838.13 \mathrm{ppb}\end{array}$ & 2125 \\
\hline G & 16.7 & $\begin{array}{c}16.7 \mathrm{ppb}(50 \mathrm{~mL} / 10 \mathrm{~mL})(50 \mathrm{~mL} / 2.5887 \mathrm{~g})= \\
1612.78 \mathrm{ppb}\end{array}$ & 4175 \\
\hline $\mathrm{H}$ & 3.17 & less than $5 \mathrm{ppb} *(50 \mathrm{~mL} / 2.5221 \mathrm{~g})=99.12 \mathrm{ppb}$ & 250 \\
\hline L - control & 0.291 & & \\
\hline Median & 4.91 & & 291.25 \\
\hline \multicolumn{4}{|c|}{ The readings for the 8 specimens and the control under the calibration curve of $5-40 \mathrm{ppb}$ are listed. } \\
\hline \multicolumn{4}{|c|}{ * Parts per billion } \\
\hline \multicolumn{4}{|c|}{ ** Determined by estimating the amount of mercury in ppb multiplied by the recorded weight of the mask. } \\
\hline
\end{tabular}

Table 2: Identification of the class type (according to the Black classification of restoration) of each tooth the amalgam was removed from by the operator for each specimen.

\begin{tabular}{|c|c|c|}
\hline Espécimen & $\begin{array}{c}\text { Operative tooth according to odontogram } \\
\text { by quadrants. (FDI tooth numbering } \\
\text { system) }\end{array}$ & $\begin{array}{c}\text { Classification of amalgam restoration } \\
\text { according to Black's classification of } \\
\text { restoration. }\end{array}$ \\
\hline A & 26 & Class II \\
\hline B & 27 & Class I \\
\hline C & 45 & Class I \\
\hline D & 16 & Class II I \\
\hline E & 37 & Class I \\
\hline F & 14 & Class II \\
\hline G & $25,26,27$ & Class II \\
\hline H & 27 & \\
\hline
\end{tabular}


The results of this study are presented in Table 1 . The 8 samples were listed alphabetically, "A-H, and the control specimen was labeled as sample "L." The mercury levels identified by the spectrophotometer in the facemasks were shown as: parts per billion (ppb), ppb in relation to the facemask, and in nanograms (ng) in relation to the facemask. Table 2 shows the class type (according to the Black classification of restoration) of each tooth the amalgam was removed from by the operator for each specimen. The atomic absorption spectrophotometer performed two readings with a calibration curve of $5 \mathrm{ppb}-40 \mathrm{ppb}$. The control facemask had 0 ppb of mercury. Graph 1 shows specimens $\mathrm{A}, \mathrm{F}$, and $\mathrm{G}$ with the highest levels of mercury identified in the facemasks (30.8ppb, $17.0 \mathrm{ppb}$, and $16.7 \mathrm{ppb}$ respectively) with a median of $4.91 \mathrm{ppb}$ of all specimens. Graph 2 shows specimens B, D, E, and H with mercury levels of $250 \mathrm{ng} /$ facemask, with a median of $291.25 \mathrm{ng} /$ facemask.

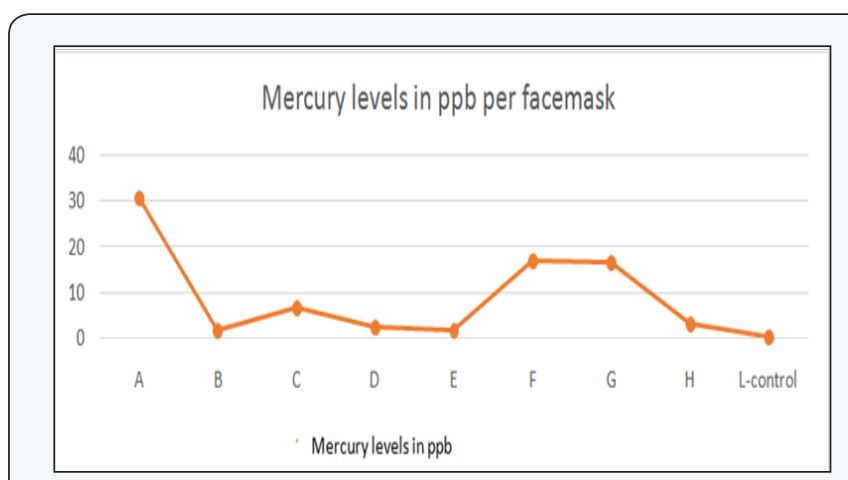

Graph 1: The results of the specimens are shown in parts per billion ( $\mathrm{ppb}$ ) after the reading of the atomic absorption spectrophotometer within a calibration curve of $5-40 \mathrm{ppb}$.

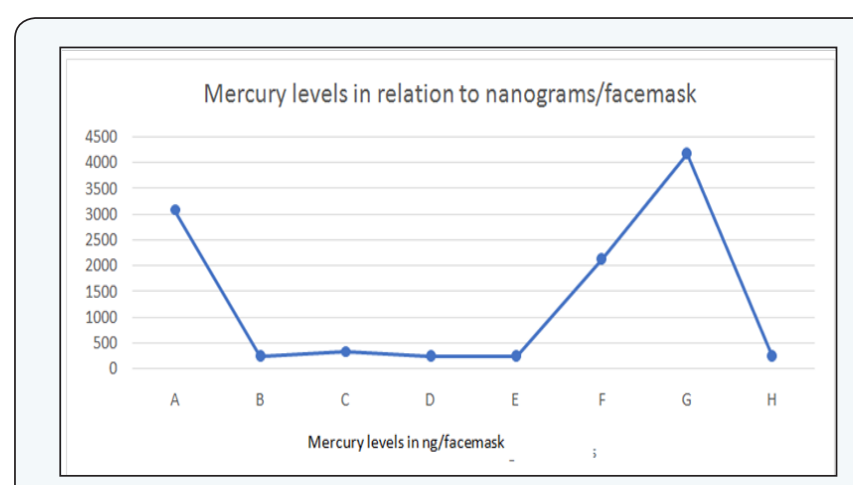

Graph 2: The mercury levels are shown in nanograms /facemask of the atomic absorption spectrograph within a calibration curve of $5-40 \mathrm{ppb}$.

\section{Discussion}

Mercury is considered highly toxic to humans and can damage vital organ systems, including the nervous, digestive, respiratory, renal, and immune systems [19]. Thus, programs at the international level are deliberately striving to eliminate the use of mercury-added products.

Inhalation of elemental mercury vapor is the most relevant route of mercury exposure. Mercury vapor in the breathing zone is inhaled into the lungs, where it is estimated that $80 \%$ is absorbed by the lung tissues [20].

There is a significant correlation between mercury contamination and work areas where mercury is produced at high levels in environmental areas such as dental offices where amalgam removal occurs [21]. Thus, inhalation of amalgam powder may contribute to mercury exposure in the working environment. Ingestion and dermal exposure are also other important routes of exposure to mercury.

In this study, the amount of mercury dispersed as aerosol in the working environment was not considered, but the surface mercury levels in the outer layer of the facemasks were analyzed. We deduced that the identification of the heavy metal on the surface of the mask was the amount of mercury not inhaled by the operator during the removal of amalgams.

It should be mentioned that the results of this study cannot be compared with the results of Rugg-Gunn et al. The average exposure level of mercury vapor when removing an amalgam restoration, without water irrigation and without ventilation, is $0.19 \mathrm{mg} / \mathrm{m}^{3}$ [11]. The results of this study show a median of $291.25 \mathrm{ng} /$ facemask and $4.91 \mathrm{ppb}$ in the reading of mercury ions. OSHA also expresses its results in vapor measurements in the work environment taken from the aerosols generated; however, the methodology of this pilot study used mass measurement through the atomic absorption spectrophotometer.

In this study, all samples were obtained using saliva ejectors. It is known that, using a saliva ejector during removal of amalgam, the operator is exposed to $168 \mu \mathrm{m} / \mathrm{m}^{3}$. It also shows that using a high-speed ejector reduces the amount of mercury to $1.5 \mu \mathrm{m} /$ $\mathrm{m}^{3}$ [20]. Thus, mercury vapor levels are considerably diminished with the use of a ejector or high speed air extractor [22].

The effectiveness of the face mask in terms of preventing the mercury from reaching the airways was not evaluated in this investigation. In addition, factors such as operator posture, use of suction systems, ventilation of the work area, contamination of the facemask due to contaminated gloves, as well as the proximity between each dental unit were not considered as variables for this study. However, in this pilot study, the type of tooth treated presents a subjective relation with the index of mercury presented in the masks.

The three samples that had the highest mercury level were those identified as A, F, and G; the three samples were obtained from upper teeth ( 2 molars, class II restored with amalgam and 1 premolar, class I restored with amalgam respectively) and the removal time was different per the type and size of the amalgam. Sample "F" was collected from an operator who used a surgical protective mask during the removal of the amalgam, and yet it showed high levels of mercury.

Sample "G" had the highest amount of mercury in terms of ng/facemask. We believe that this reading originated from the 
fact that the operator removed amalgams from three different maxillary teeth during the same session. The rest of the samples only involved the removal of one single amalgam tooth per session. Perhaps, removing more dental amalgams in a single session increases the levels of mercury identified on the surface of the masks, however, more samples would be needed to confirm this claim.

We believe that the fact that no operator used indirect vision at the time of amalgam removal lead to a closer proximity of operator to patient to visualize the amalgam that had to be removed. Therefore, this proximity resulted in a higher amount of contaminated aerosols reaching the operator's face, leading to a higher mercury reading from the samples obtained from the maxilary teeth.

Surgical facemasks can help block larger droplets of particles, spills, sprays or splashes, which may contain germs, viruses and bacteria, so they won't reach the nose or mouth. However, they are used primarily to protect patients from the health workers, and reduce their exposure to saliva and respiratory secretions and yet, these surgical facemasks do not create a tight seal against the skin or filter very small airborne pathogens, such as those responsible for airborne diseases [23].

There are studies that show the relationship between the manipulation and removal of amalgam per week with the levels of mercury found in the dentist. Therefore, when an activity poses a threat to human health or the environment, precautionary measures should be taken even if some cause and effect relationships have not been established scientifically [24].

It is necessary for undergraduate programs in dentistry to focus on courses, seminars or academic modules that address issues of occupational safety, biosafety and infection control, as well as the risk of using hazardous substances such as mercury. Students should be capable of applying these protocols effectively. This will benefit oral health professionals by reducing their exposure to this toxic heavy metal and will reduce the environmental impacts of mercury on solid waste, air, and water residuals.

Exposure to mercury and the possibility of reducing it in the dental workplace remains a challenge. This is a pilot study and these results should be taken with caution and merit more cases and a methodological rigor for the control of the variables.

\section{Conclusion}

Levels of quantifiable mercury were identified on the outer surface facemask of the personal protective equipment when removing dental amalgams that round up to $291.25 \mathrm{ng} /$ masks.

Greater number of samples and the establishment of various variables (operator position, suction use) are needed to statistically relate the impact of the mercury levels identified on the facemasks after the amalgam removal.

Following the programs in occupational health, biosecurity and infection control in dentistry will allow us to work with high standards of safety and quality in the work area.

\section{Recommendations}

There are measures that dentists can take to reduce exposure to mercury that can be obtained from the results of this pilot study, these are:

A. Use indirect vision at the time of amalgam removal.

B. Use appropriate working positions during a dental procedure (ergonomics).

C. Use the personal protective equipment which includes: gloves, protective glasses, disposable gowns, protective mask, face mask, dental loupes; in order to protect dentists and dental workers from mercury vapor or amalgam particles during the procedures.

\section{Acknowledgements}

The authors want to thank Alberto Arriola Valdés, Director Faculty of Dentistry UAG, Ignacio Gárate Villaseñor, Research Coordination, Faculty of Dentistry, UAG. María Cecilia Rodríguez Soto, Committee Occupational Safety, Faculty of Dentistry, UAG and Lydia Olvera Ávila, Investigator CIDI UAG.

\section{References}

1. World Health Organization (2009) Future Use of Materials for Dental Restoration, WHO, Geneva, Switzerland, p. 1-65.

2. Anusavice KJ (2003) Philips' Science of dental materials: Elsevier $11^{\text {th }}$ (edn),

3. IAOMT (2016) A comprehensive review of the toxic effects of mercury in dental amalgam fillings on the environment and human health (2016) The international academy of oral medicine and toxicology, p. $1-26$.

4. Taut C (2013) Dental Amalgam: is this the end? Journal of Irish Dental Association 59(6): 311-317.

5. SCENIHR (2015) The Safety of Dental Amalgam and Alternative Dental Restoration Materials for Patients and Users, pp. 1-116.

6. Echeverria D, Aposhian HV, Woods JS, Heyer NJ, Aposhian MM, et al. (1998) Neurobihavioral effects from exposure to dental amalgam $\mathrm{Hg}$ (o) new distinctions between recent exposure and $\mathrm{Hg}$ body burden. FASEB J 12(11): 971-980.

7. DAMS (2014) Dental Amalgams Mercury Solutions.

8. Svare (1981) The effect of dental amalgams on mercury levels in epired air. J Denr Res 60(9): 1668-1671.

9. Brune D, Hensten-Pettersen A, Beltsebrekke H (1980) Exposure to mercury and silver during removal of amalgam restorations. Scand J Dent 88(5): 460-463.

10. American Dental Association (2007) The best management practice for amalgam waste.

11. Rugg-Gunn AJ, Welbury RR, Toumba J (2001) British Society of Paediatric Dentistry: a policy document on the use of amalgam in Paediatric Dentistry. Int J Paediatric Dent 11(3): 233-238.

\section{ADA (2016) The American Dental Association.}

13. Asociacion Odontologica Panameña (2011) Gobierno de la Republica de Panamá. 
14. Leyva Ruiz G (2009) El cubre bocas ó mascarilla, un recurso para garantizar la seguridad del personal de salud y del paciente. Enfermeria Universitaria. ENEO -UNAM. Numero Especial Influenza Julio, p. 37-41.

15. Garza Garza AM (2016) Control de infecciones y biseguridad en odontologia Mexico DF: El Manual Moderno.

16. Lee SA, Grinshpun SA, Reponen T (2008) Respiratory performance offered by $\mathrm{N} 95$ respirators and surgical masks: human subject evaluation with $\mathrm{NaCl}$ aerosol representing bacterial and viral particle size range. Ann Occup Hyg 52(3): 177-185.

17. Derrick JL, Gomersall CD (2005) Protecting healthcare staff from severe acute respiratory syndrome: filtration ca- pacity of multiple surgical masks. J Hosp Infect 59(4): 365-368.

18. Secretaria de Salud (2010) Promoción de la Salud SSA México, p. 1-5.

19. Akesson I, Shutz A, Attewell R, Skerfving S, Glantz PO (1991) Status of mercury and selenium in dental personnel: impact of amalgam work and own fillings. Arch Envir Health 42(2): 102-109.
20. United Nations Environment Programme (2002) Global Mercury Assessment Report.

21. Baelum J, Pockel H (2007) Reference document on exposure to metallic mercury and the development of symptoms with emphasis on neurological and neuropsychological diseases or complaints. Odense University Hospital, Department of Occupational and Enviromental Medicine, p. 1-20.

22. Ritchie KA, Burke FJ, Gilmour WH, Macdonald EB, Dale IM, et al. (2004) Mercury vapour levels in dental practices and body mercury levels of dentists and controls. British Dental Journal 10(197): 625-632.

23. Centros para el Control y la Prevención de Enfermedades (2016) Equipo de protección personal (EPP) para trabajadores de la salud.

24. Science and Environmental Health Network (SEHN) (1998) Science and Environmental Health Network (SEHN).

Your next submission with Juniper Publishers
will reach you the below assets
- Quality Editorial service
- Swift Peer Review
- Reprints availability
- E-prints Service
- Manuscript Podcast for convenient understanding
- Global attainment for your research
- Manuscript accessibility in different formats
( Pdf, E-pub, Full Text, Audio)
- Unceasing customer service
Track the below URL for one-step submission
https://juniperpublishers.com/online-submission.php

